\title{
Effect of Equal Channel Angular Pressing on the Properties of Rolled Commercial Purity A1100 Aluminum
}

mohammed abdelkrim boussaada ( $\square$ boussadamedabdelkrim@gmail.com )

University of Badji Mokhtar Annaba: Universite Badji Mokhtar Annaba https://orcid.org/0000-00016443-6944

ABDELMALEK MEBAREK

ABDELAZIZ BOUASLA

MOHAMED ZAAF

\section{Research Article}

Keywords: Aluminum, ECAP, micro hardness, stress, shear, die of ECAP

Posted Date: February 16th, 2022

DOI: https://doi.org/10.21203/rs.3.rs-1334718/v1

License: (c) (i) This work is licensed under a Creative Commons Attribution 4.0 International License.

Read Full License 


\section{Abstract}

Commercial grade A1100 aluminum specimens, widely used in deep drawing, is subjected to rolling followed by severe plastic deformation by Equal Channel Angular Pressing (ECAP). The ECAP die is designed and built in 42CrMo4 steel, hyper-hardened. It has a bent channel with an internal angle $\varphi=115^{\circ}$ and an external angle $\psi=8^{\circ}$. The used deformation paths are the conventional route $A$ as well as a nonconventional route noted $\mathrm{Ci}$. The ECAP process is carried out at room temperature. The lowering speed of the movable crosshead of the press is $0.5 \mathrm{~mm} / \mathrm{s}$. The rolled and then extruded aluminum properties are studied by means of micro-hardness measurements, tensile tests and X-ray diffraction. Hardening is observed from the first pass, for both routes. The ultimate tensile strength presents a small variation for route $\mathrm{A}$ and decrease for route $\mathrm{Ci}$. The elongation to failure increase for both $\mathrm{A}$ and $\mathrm{Ci}$ routes. The average grain diameter is on the order of $2,9 \mu \mathrm{m}$ after rolling and $1,3 \mu \mathrm{m}$ after ECAP process in one pass.

\section{Introduction}

There is an increasing interest in the ultrafine-grained materials due to their exceptional properties [1-7]. It is well known that the reduction in grain sizes in metals and metal alloys has an effect on increasing the mechanical strength without decreasing the ductility properties as in the case of work hardening [810]. This advantage is of great interest in manufacturing metals and metal alloys with an extremely fine grain size [11-14].

Equal channel angular pressing (ECAP) is a severe plastic deformation technique that produces very finegrained of bulk metallic materials. This is possible because the channels of the ECAP bend have identical cross-sections and, therefore, the extrusion can be repeated in order to introduce a high rate of deformation and ultimately refine the grain size to the theoretical limit imposed by the characteristics of the metal or metal alloy used.

The ECAP process, developed in the early 1980s by Segal et al. [15], involved extruding a sample through a die with two channels of equal cross-section forming a bend at their intersection. Figure 1 shows a schematic of an ECAP die at a $90^{\circ}$ bend. The sample, forced to move from the inlet channel to the outlet channel, undergoes a large deformation by simple shearing at the plane of intersection of the two channels. The considerable interest in the ECAP process is widely reported by Beyerlein and Toth [16]. This interest is mainly due to the ability of ECAP to control the microstructure and properties of crystalline metals.

The equivalent plastic deformation is given by the formula proposed in 1996 by Iwahashi et al. [17]:

$\epsilon^{P}=\frac{1}{\sqrt{ } 3}\left[2 \cot \left(\frac{\phi}{2}+\frac{\Psi}{2}\right)+\Psi \operatorname{cosec}\left(\frac{\phi}{2}+\frac{\Psi}{2}\right)\right.$

The deformations accumulate after each pass through the extruder, therefore the equivalent deformation obtained after $\mathrm{N}$ cycles is: 
$\epsilon^{P}$ total $=N \varepsilon^{p}$

More recently, Goforth et al. [18] simplify Eq. (1) to:

$\epsilon^{P}=\frac{1}{\sqrt{ } 3}\left[2 \cot \left(\frac{\phi}{2}+\frac{\Psi}{2}\right)+\Psi\right](2)$

An investigation was carried out by Aida et al. [19] to compare the equations (1) and (2). They showed that they are quasiequivalent. Indeed, for the extremities of $\psi$ (with $\varphi$ fixed) the value of $\varepsilon^{p}$, is the same, as for the intermediate values taken by $\psi$, the variation in deformation does not exceed $5 \%$

In ECAP, the specimen can be re-injected a large number of times into the die and a high strain rate can be achieved [20]. The way in which the ingot is re-introduced into the die is called the deformation route. Although many routes can be theoretically defined for practical purposes, four fundamental routes are exploited by researchers [21] (Fig. 2)

In order to understand the nature of grain refinement to deformation associated with $\mathrm{N}$ passes, and in particular the influence of the processing route, it is necessary to study the shear plane processes that develop in each specimen during repeated passes through the die. These patterns take the form of the dominant shear directions, for the classical routes A, B and C[21-23]. In the Bc route, the two shear directions lie on planes that intersect at $120^{\circ}$. In contrast, road A has two shear planes that intersect at $90^{\circ}$. Road C is subjected to shear deformation in the same plane but the direction of shear is reversed after each pass.

In this work, we investigated the extrusion of commercially pure A1100 aluminum, which is widely used in deep drawing. In order to monitor the effect of preliminary strain hardening on grain refinement, we rolled the test specimens at a thickness reduction rate of $₫=60 \%$ in one pass

\section{Materials And Methods}

The rolling was carried out on a laboratory rolling mill shown in Fig. 3.

This study was conducted through the following steps:

- The Vickers micro-hardness profile for each pass from one to eight.

- The tensile curves for each pass.

- X-ray diffraction, for the determination of the average grain size.

The studied deformation routes were the classical A route as well as a non-classical route which we will note $\mathrm{Ci}$ (route $\mathrm{C}$ inversed) and which is presented in Fig. 4. The successive passes thus consist of a $180^{\circ}$ rotation around the longitudinal axis and $180^{\circ}$ rotation around the transverse axis, as described by F.HadjLarbi et al. [24]. 
We made an ECAP die with an internal angle $=115^{\circ}$ and an external angle $\psi=8^{\circ}$. This corresponds, according to Iwahashi [17], to an equivalent deformation of 0.72 for one pass.

This die of ECAP is made of low-alloy 42CD4 steel. After machining the channel with a digital milling machine followed by grinding, it underwent a hyper-quench heat treatment. Its final hardness is around $60 \mathrm{HRC}$. The channel has a square section of $10 \times 10 \mathrm{~mm} 2$. A view of this die is shown in Fig. $5 \mathrm{a}$ and Fig. 5b.

Figure 5 -a. View of the die of ECAP,$=115^{\circ}$ et $\psi=8^{\circ}$

ECAP at the end of a test

The A1100 aluminum used in the annealed state has the following composition (in\%),obtained by X-ray fluorescence spectrometry( Table 1).

Table 1

Composition of the A1100 in the annealed state

\begin{tabular}{|llllllll|}
\hline Si & Fe & Cu & Mn & Zn & Ti & Others & Al \\
\hline 0,19 & 0,47 & 0,05 & 0,05 & 0,006 & 0,1 & 0,034 & 99,1 \\
\hline
\end{tabular}

The test specimens, after rolling, have the following dimensions: $2 \mathrm{~mm}$ thick, $10 \mathrm{~mm}$ wide and $50 \mathrm{~mm}$ long. Thus, for each test, five test specimens are sandwiched together to fill the $10 \times 10 \mathrm{~mm}^{2}$ section channel. Two uncontrolled aluminum sacrificial specimens were sandwiched between three A1100 aluminum specimens. Figure $6 a$ shows the arrangement of the five sandwiched specimens. A view of this assembly at the exit of the channel is shown in Fig. $6 \mathrm{~b}$. To reduce friction, the samples and the die are greased with a molybdenum disulphide based grease $\mathrm{MoS}_{2}$.

\section{Resultsand Discussion \\ 3.1. Slip lines}

It is found that the extruded specimens show on the surface the trace of the activated sliding planes, observable macrographically. As an example, Fig. 7 shows these sliding lines on the surface of an aluminum specimen, at position 1, extruded in a single pass. These planes are arranged at $45^{\circ}$ to the extrusion direction (longitudinal axis of the specimen)

\subsection{Micro-hardness $\mathrm{Hv} 0,2$}

After the tests, the specimens undergo an HV micro-hardness measurement of $200 \mathrm{gf}$ load for 10 seconds (the average of 15 measurements was realized along each specimen in the direction of extrusion). The study was carried out by monitoring the micro-hardness of the samples classified according to two parameters: 
- The position of the specimen in the channel of ECAP position 1, 3 or 5.

- The route used, $\mathrm{A}$ or $\mathrm{Ci}$.

The Vickers micro-hardness profile $\mathrm{Hv}_{0.2}$ is shown in Fig. 8 . We can note that for the 3 positions of the specimens in the channel, the hardening appears from the first pass. It does not seem to evolve much for the following passes. Overall and for the 3 positions, the $\mathrm{Ci}$ route seems to give a higher hardening than the $A$ route.

We can note that for the 3 positions of the specimens in the channel, the hardening appears from the first pass. It does not seem to evolve much for the following passes. Overall and for the 3 positions, the $\mathrm{Ci}$ route seems to give a higher hardening than the A route.

\subsection{Tensile test}

The tensile tests were carried out on a ZWICK $20 \mathrm{kN}$ machine. The recorded tensile curves show a small plastic hardening range and a non-linear elastic range for the rolled and extruded specimens. As an example, Fig. 9 shows the curves recorded on a specimen:

a- before rolling. b- after rolling. $\mathrm{c}$ - after ECAP/2nd pass/position3/route $\mathrm{Ci}$. The ultimate tensile strength $\sigma_{\max }$ and the elongation to failure $A(\%)$ corresponding are presented on Table 2 .

Table 2

Ultimate strength and elongation to

failure

\begin{tabular}{|llll|}
\hline & (a) & (b) & (c) \\
\hline$\sigma_{\max }(\mathrm{MPa})$ & 96,1 & 125,8 & 100,5 \\
$\mathrm{~A}(\%)$ & 10 & 11,9 & 16,9 \\
\hline
\end{tabular}

The results of the variation of the ultimate tensile strength omax and the elongation to failure $A(\%)$ as a function of the number of passes are presented by Fig. 10a and Fig. 10b for the three positions 1, 3 and 5 of the specimens. Compared to the only rolled specimen, for route $A, \sigma_{\max }$ vary little and $A(\%)$ increase while for route $\mathrm{Ci}, \sigma_{\max }$ decrease and $\mathrm{A}(\%)$ increase.

\subsection{X-ray diffraction}

The X-ray diffraction patterns allowed us to determine the average grains diameter using the DebyeScherrer method. The relation used is:

$$
\mathrm{D}=\frac{\mathrm{k} \lambda}{\mathrm{W} \cos \theta}
$$


Where : D:average grain diameter $(\mu \mathrm{m}) . \mathrm{k}$ :shape factor (scherrer constant $=0,9) . \lambda: \mathrm{x}$-ray wave length( $0,15406 \mu \mathrm{m}$ ). W: width at half maximum (radians). $\theta$ : peak position. The X-ray diffraction was performed on a ULTIMAT IV Rigaku diffractometer. Figure 11 shows the diffraction peaks recorded on :a-Sample after rolling. b-Sample rolled and then extruded in position 1, in 1 pass. $\mathrm{c}$ and d-Sample rolled and then extruded in position 1 , in 2 passes and following respectively route $A$ and route $\mathrm{Ci}$. Table 3 summarizes the average grain diameters obtained according to the number of passes and the route, for a sample in position 1 in the channel.

Table 3

Average grain diameters

\begin{tabular}{|ll|}
\hline Sample & $\begin{array}{l}\text { Average Grain } \\
\text { Diameter }(\mu \mathrm{m})\end{array}$ \\
\hline Sample rolled & 2,88 \\
\hline Sample rolled then extruded in position 1 in 1 pass & 1,27 \\
\hline Sample rolled then extruded in position 1 in 2 passes ( route A ) & 1,97 \\
\hline Sample rolled then extruded in position 1 in 2 passes(route $\mathrm{Ci}$ ) & 1,50 \\
\hline
\end{tabular}

\section{Conclusion}

An equal channel angular pressing die with $\varphi=115^{\circ}$ and $\psi=8^{\circ}$ was carried out in order to study the hardening of $\mathrm{A} 1100$ aluminum after ECAP process. The routes used were route $\mathrm{A}$ and route $\mathrm{Ci}$.The specimens were rolled before extrusion. The parameters monitored were the number of passes and the position of the sample in the transverse direction of the extruder channel. The main results are summarized below.

- Hardening is observed from the first pass, regardless of the position of the sample and the route used.

- The number of passes has small influence on the curing process.

- Hardening is not homogeneous along a cross section. It is at its maximum towards the inner angle $\varphi$ of the bend and at its minimum towards the outer angle $\psi$.

- The ultimate tensile strength seems to be independent with the number of passes for route $A$ and decrease compared to the only rolled specimen for route $\mathrm{Ci}$. The position 1, 2 or 3 of the specimens in the channel seems to have little influence.

- The elongation to failure increase compared to the rolled-only specimen for both A and Ci routes. The number of passes seems to have small influence.

- The average grain diameter obtained on a specimen in position 1, rolled and then extruded in one pass, is on the order of $1,3 \mu \mathrm{m}$. 


\section{Declarations}

\section{Conflict of Interest}

No conflict of interest exists.

We wish to confirm that there are no known conflicts of interest associated with this publication and there has been no significant financial support for this work that could have influenced its outcome.

\section{Funding}

No Funding was received for this work.

The authors declare that no founds, grants, or other support were received during the preparation of this manuscript

\section{Intellectual Property.}

We confirm that we have given due consideration to the protection of intellectual property associated with this work and that there are no impediments to publication, including the timing of publication, with respect to intellectual property. In so doing we confirm that we have followed the regulations of our institutions concerning intellectual property.

\section{Research Ethics}

We further confirm that any aspect of the work covered in this manuscript that has involved human patients has been conducted with the ethical approval of all relevant bodies and that such approvals are acknowledged within the manuscript.

\section{Authorship}

We attest that all authors contributed significantly to the creation of this manuscript.

We confirm that the manuscript has been read and approved by all named authors.

We confirm that the order of authors listed in the manuscript has been approved by all named authors.

\section{Contact with the Editorial Office}

The Corresponding Author declared on the title page of the manuscript is:

BOUSSAADA MOHAMMED ABDELKRIM

Laboratory of metallic materials shaping, Badji Mokhtar University BP 12 -23000 Annaba-Algeria e-mail :medabdelkrim.boussada@univ-annaba.org / boussadamedabdelkrim@gmail.com 
This author submitted this manuscript using his account in EM submission site of the jounal "THE INTERNATIONAL JOURNAL OF ADVANCED MANUFACTURING TECHNOLOGY“.

We confirm that the email address shown below is accessible by the Corresponding Author.

[medabdelkrim.boussada@univ-annaba.org / boussadamedabdelkrim@gmail.com]

We understand that this author is the sole contact for the editorial process. He is responsible for communicating with other authors as the corresponding author, on progress, review submissions and final proof approval.

\section{We the undersigned agree with all of the above.}

\section{References}

1. Bouasla A, Merabtine R, Guérin S, Chevalier JP,Adv. Eng. Mater., 10,N8, 731-736

2. Valiev RZ, Langdon TG (2006) Prog Mater Sci 51:881-981

3. Danaf EA, Soliman MS, Almajid AA, El-Rayes MM (2007) Mater Sci Eng A 458:226-234

4. Xu J, Zhu X, Shi L, Shan D, Guo B, Langdon TG (2015)Adv. Eng. Mater., Volume17, Issue7,1022-1033

5. Akbarzadeh B, Gorji H, Bakhshi-Jooybari M, Jamaati R, Javad M (2021) Int J of Adv Manuf Technol 113:2175-2191

6. Agarwal KM, Tyagi RK, Choubey V, Kuldeep K, Saxena (2021) Adv. in Mater. and Proc. Techn., 1-15. doi.org/10.1080/2374068X.2021.1878705

7. Wang YC, Afifi MA, Cheng X, Li S, Langdon TG (2020) Adv Eng Mater 22:1901040

8. May J, Amberger D, Dinkel M, Hoppel HW, Goken M (2008)Mater. Sci. Eng. A,481-484

9. Valiev RZ, Murashkin MY, Straumal B (2010)Materials Science Forum Vols.633-634321-332

10. Biniyazan F, Soleimanimehr H (2021) Iran J Sci Technol Trans Mech Eng 45:727-739

11. Ma Y, Han FY, Liu C, Li MZ (2020) Acta Metall Sinica (English Letters) 33:233-242

12. Huang R, Zhu D, Liao X, Yan Q (2020)Journal of electronic materials, Vol. 49, No. 4,

13. Volokitina IE, Science M, Treatment H (2021) Nos. 3-4, July, 2021 (Russian Original Nos. March April 63:3-4

14. Romero-Reséndiz L, Flores-Rivera A, Figueroa IA, Braham C, Reyes-Ruiz C, Alfonso I, González G (2020) International Journal of Minerals, Metallurgy and Materials, Volume 27, Number 6, June Page 801

15. Segal VM, Reznikov VI, Drobyshevskiy AE, Kopylov VI (1981) Russ Metall 1:99-105

16. Beyerlein IJ, Toth LS (2009) Prog Mater Sci 54:427-510

17. Iwahashi Y, Horita Z, Nemoto M, Langdon TG (1996) Scripta Mater 35:143-146

18. Goforth RE, Hartûrig KT, Cornwell LR (eds) (2000) Eds. Lowe \&Valiev. Kluwer academic publishersPays-Bas 
19. Aida T, Matsuki K, Horita Z, Langdon TG (2001) Scripta Mater 44:575

20. Segal. VM (1995) Mater Sci Eng A 197:157-164

21. Nakashima K, Horita Z, Nemoto M, Langdon TG (2000) Mater Sci Eng:A 281:82

22. Furukawa M, Iwahashi Y, Horita Z, Nemoto M, Langdon TGMater. Sci. Eng. A,1998,257,328-332

23. Segal VM (2002) Mater Sci Eng A 338:331-344

24. Hadj-Larbi F, Alili B, Bradai D, Helbert AL T.Baudin, Techniques de l'ingénieur,10 septembre 2018, p.9

\section{Figures}

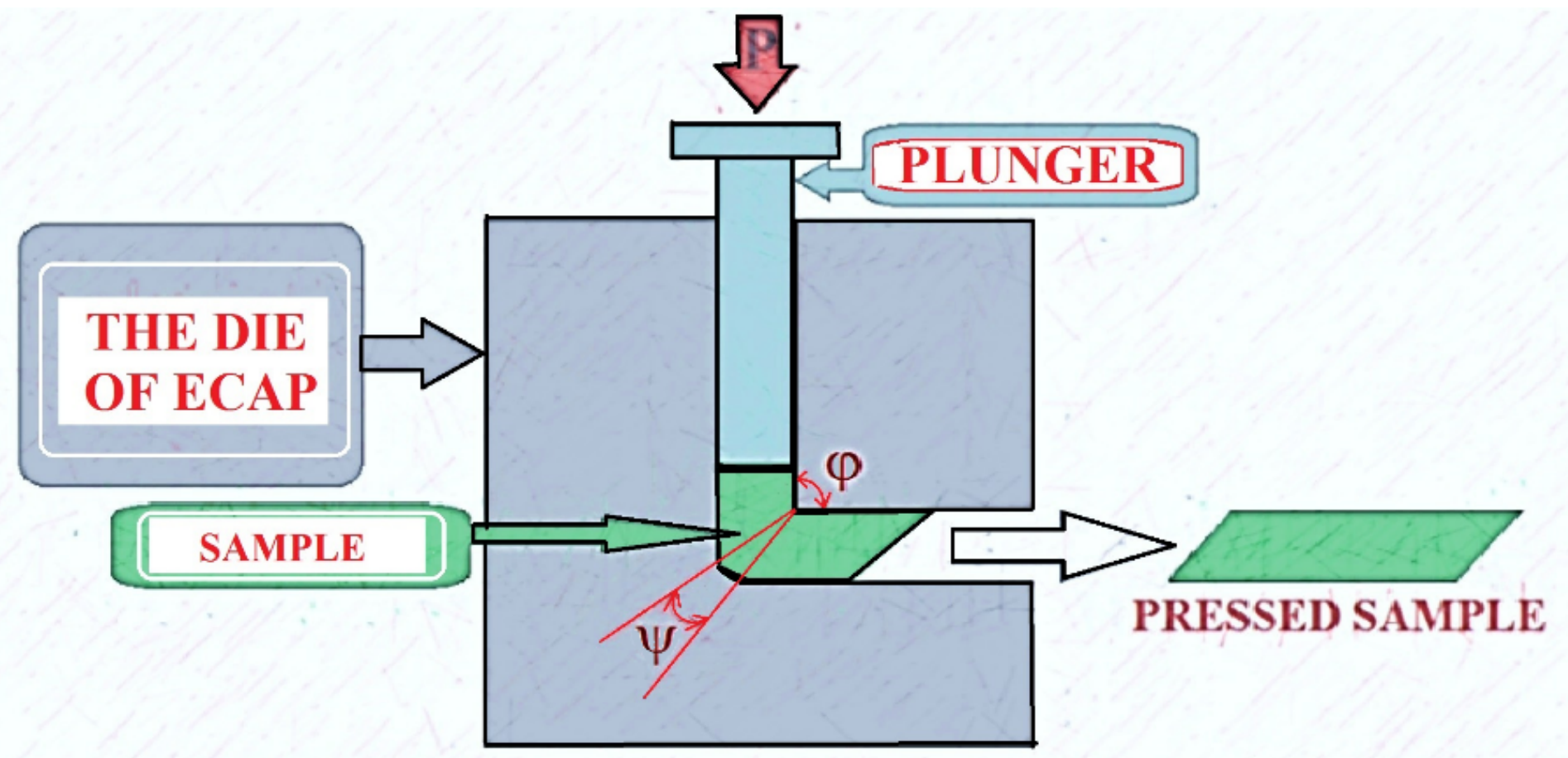

Figure 1

The principle of ECAP 

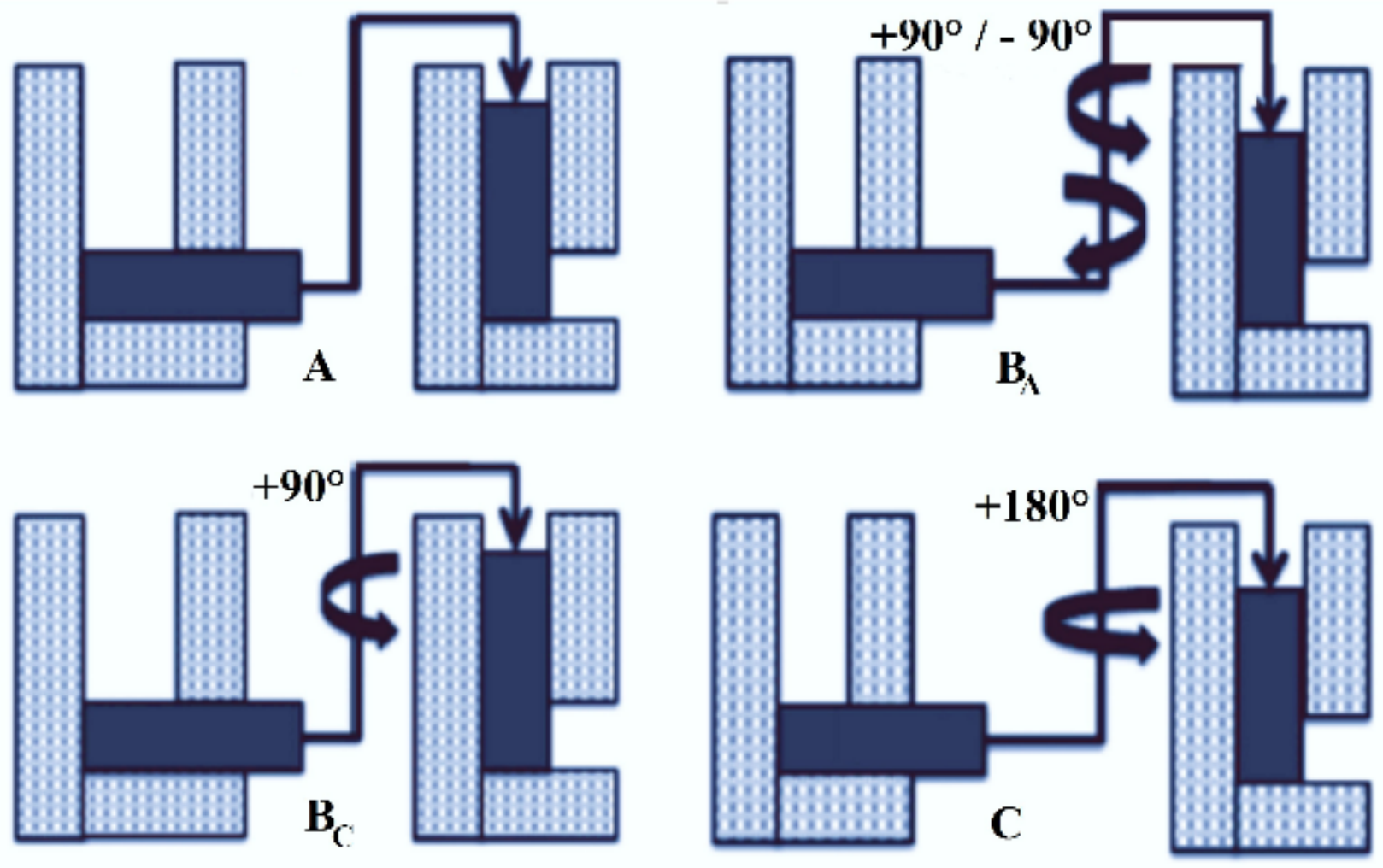

Figure 2

Schematic diagram of the ECAP deformation routes [21] 


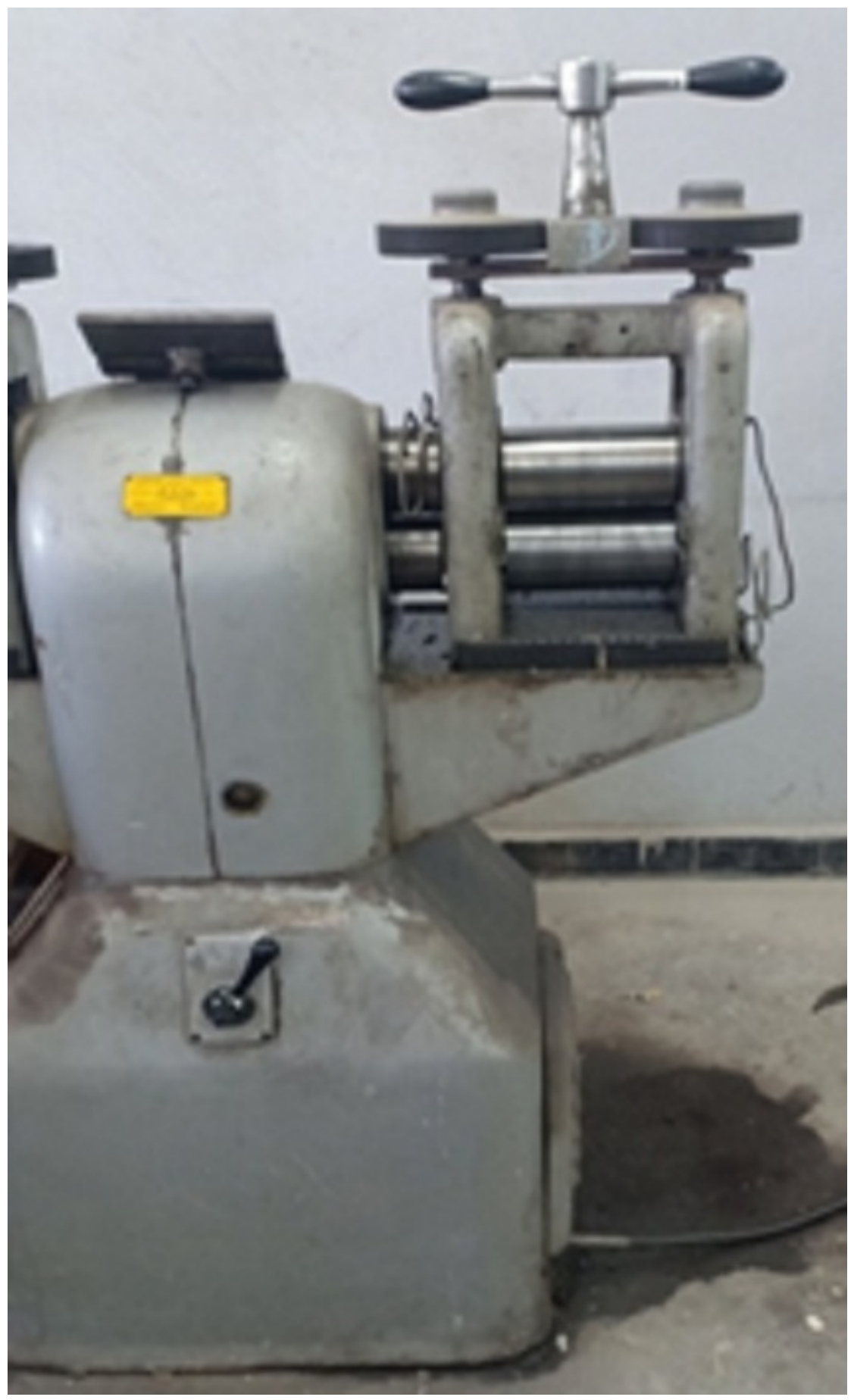

Figure 3

Laboratory rolling mill 


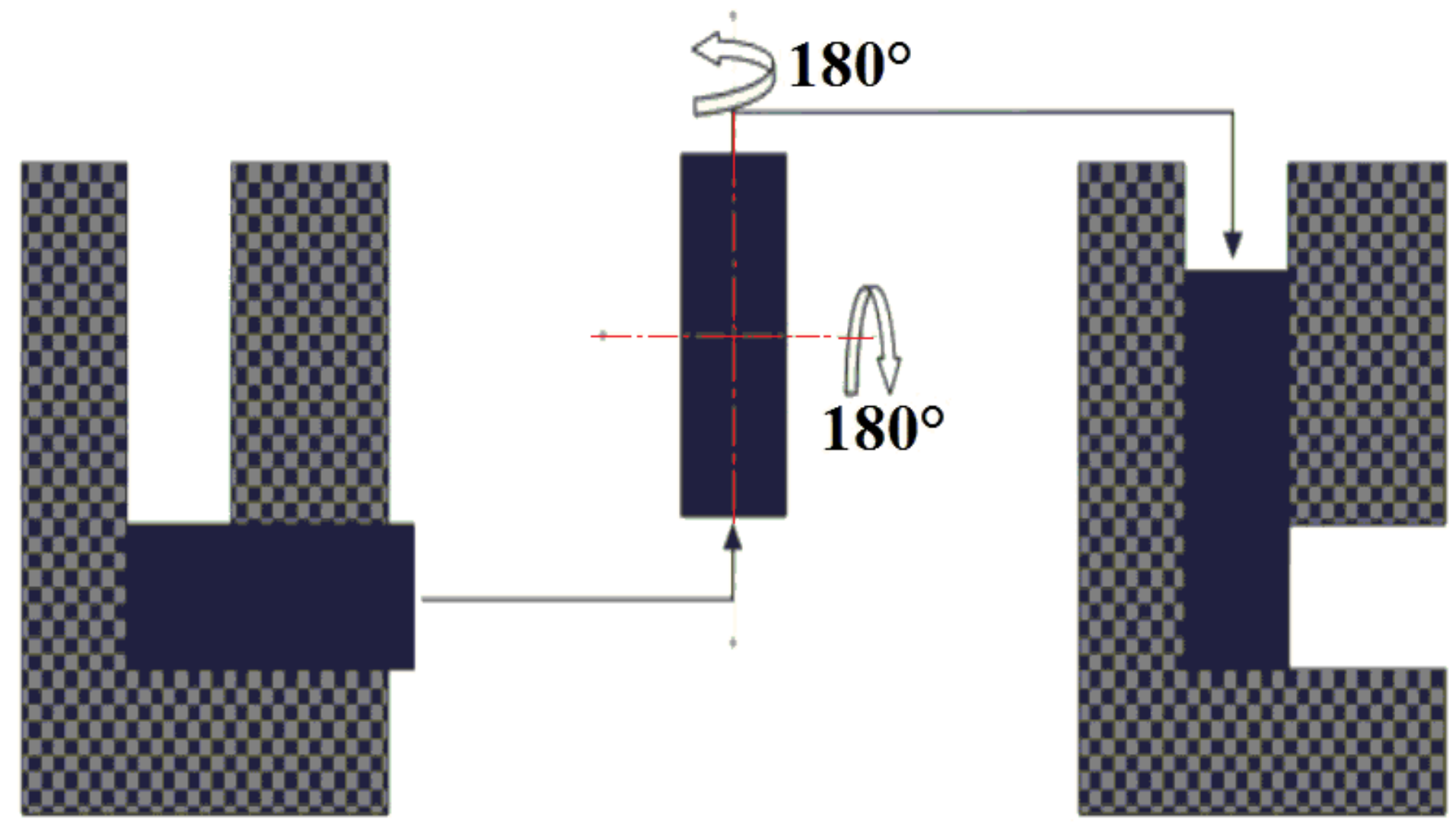

Figure 4

Route $\mathrm{Ci}$
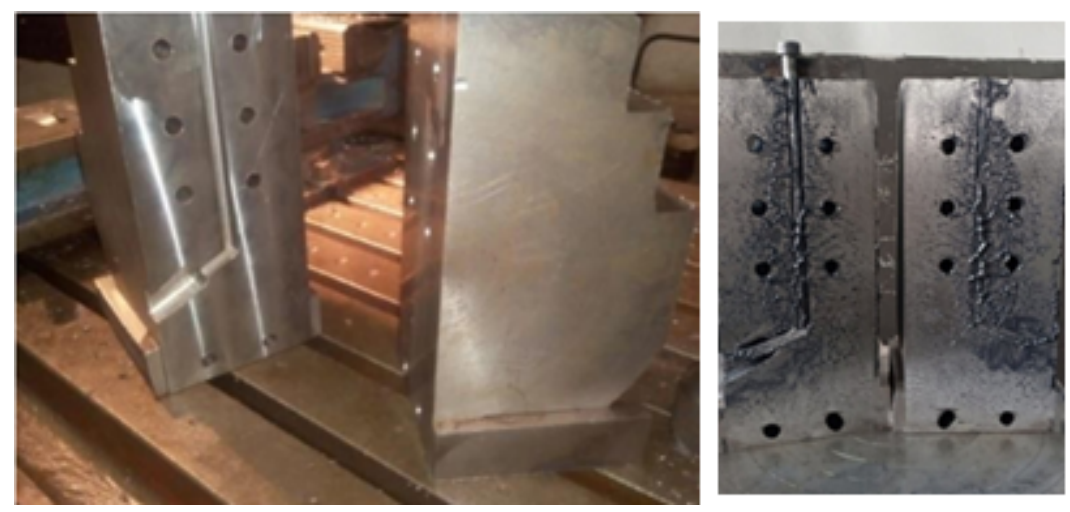

Figure 5

a. View of the die of ECAP,$q=115^{\circ}$ et $\psi=8^{\circ}$

b. View of the open die of ECAP at the end of a test 

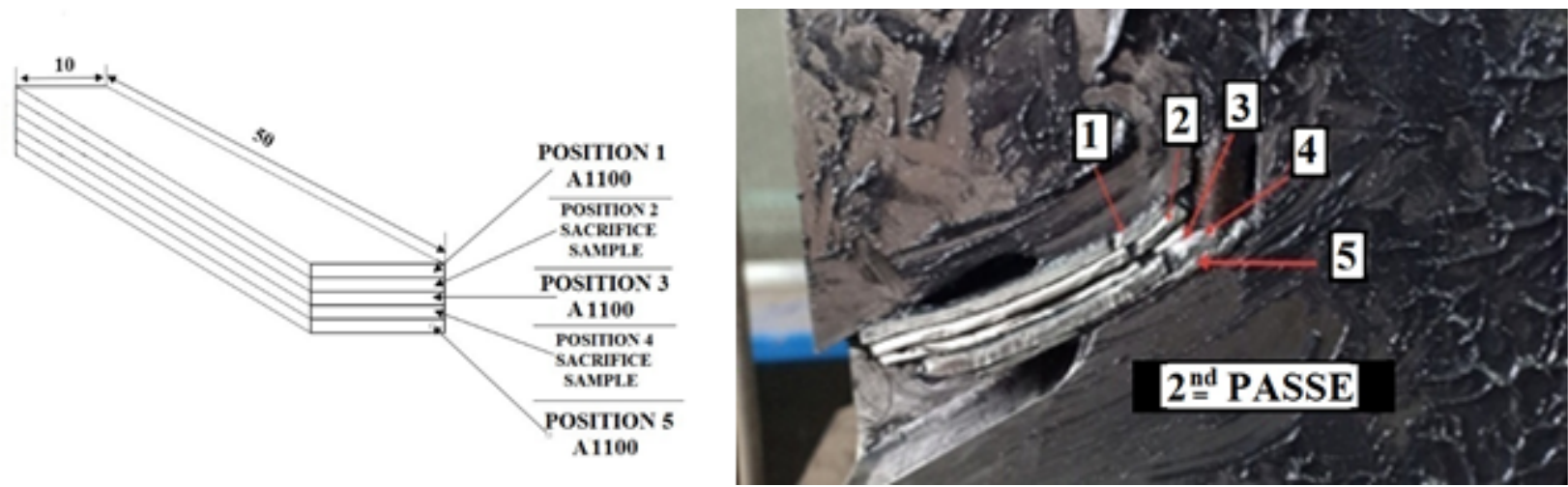

Figure 6

a.Sandwich samples

b.The samples at the output of the channel

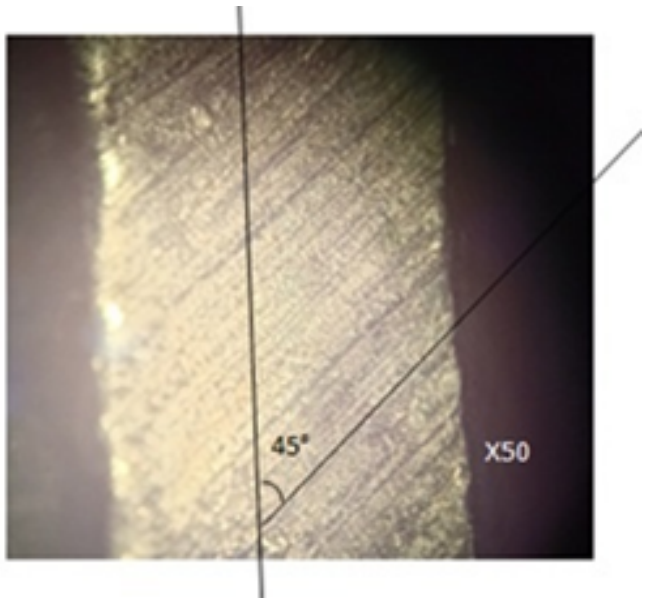

Figure 7

Slip lines 
Microhardness Profil as a Fonction of the Number of PassesPosition 1

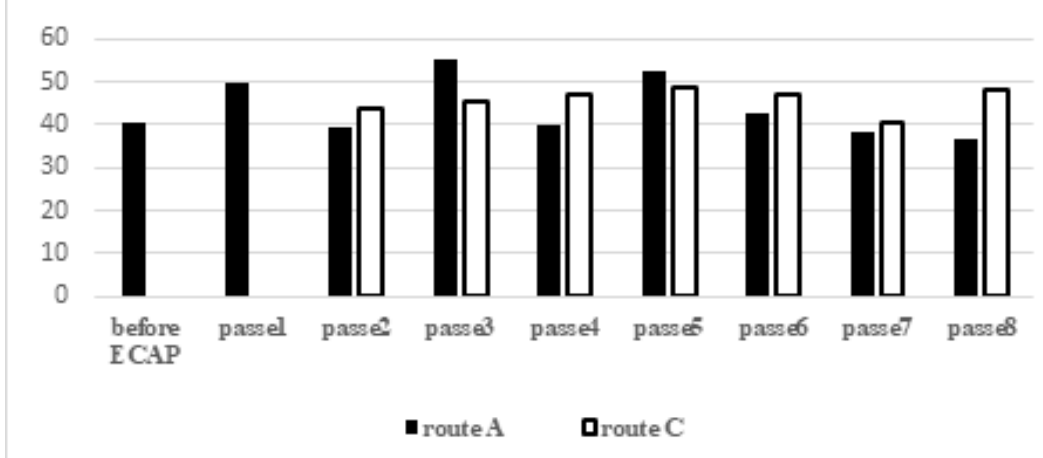

Microhardness Profil as a Fonction of the Number of PassesPosition 3

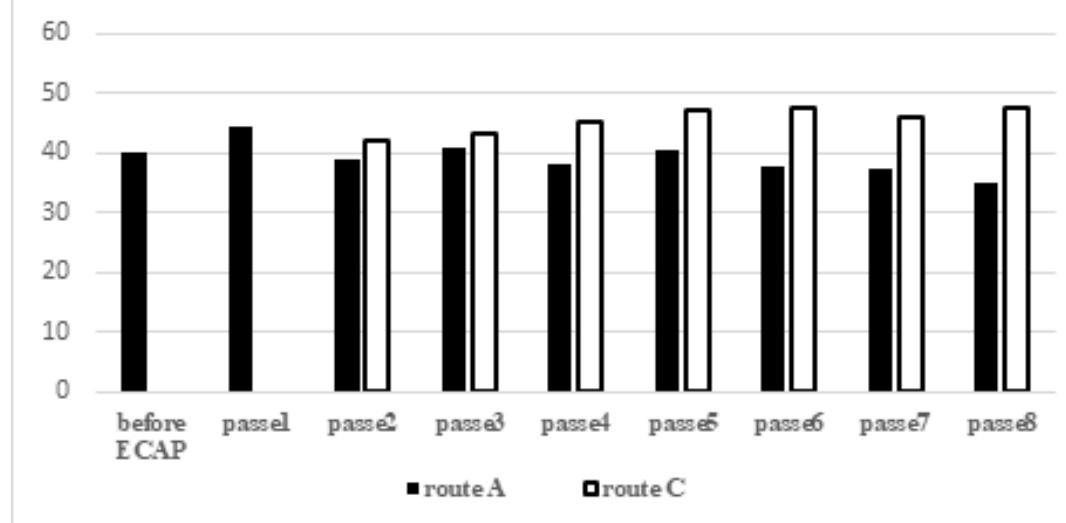

Microhardness Profil as a Fonction of the Number of PassesPosition 5

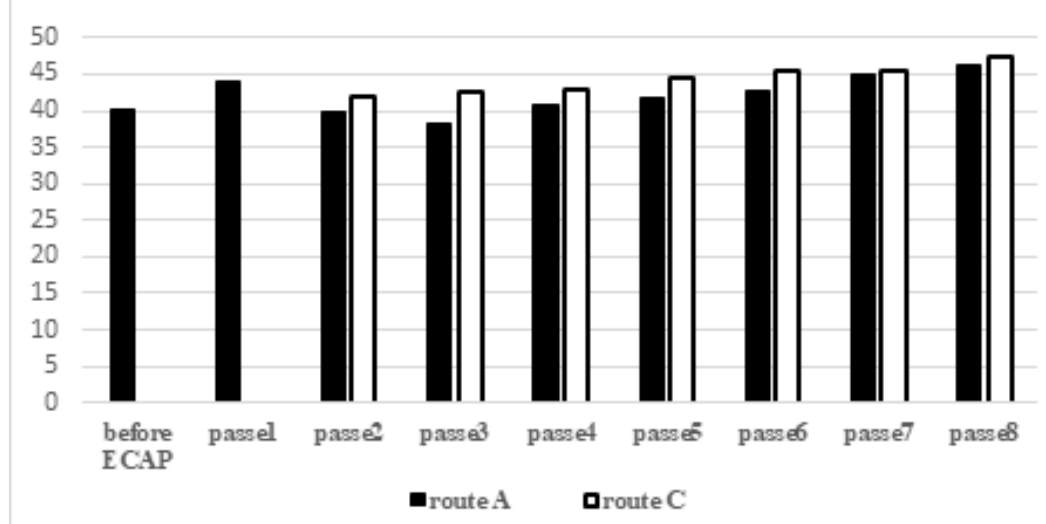

Figure 8

Vickers micro-hardness profile $\mathrm{Hv}_{0.2}$ 

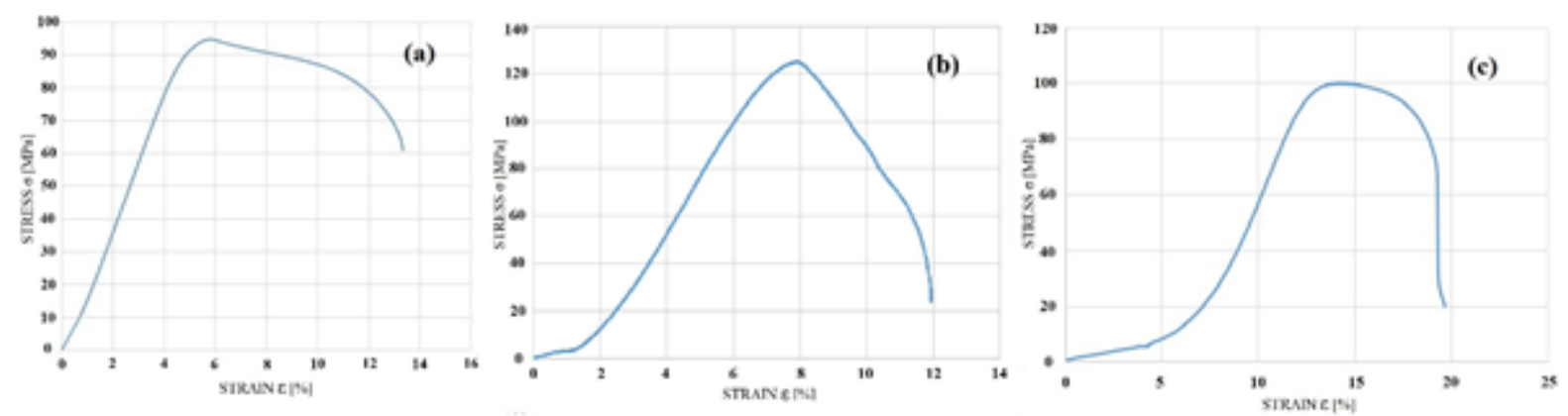

Figure 9

Evolution of the tensile curve
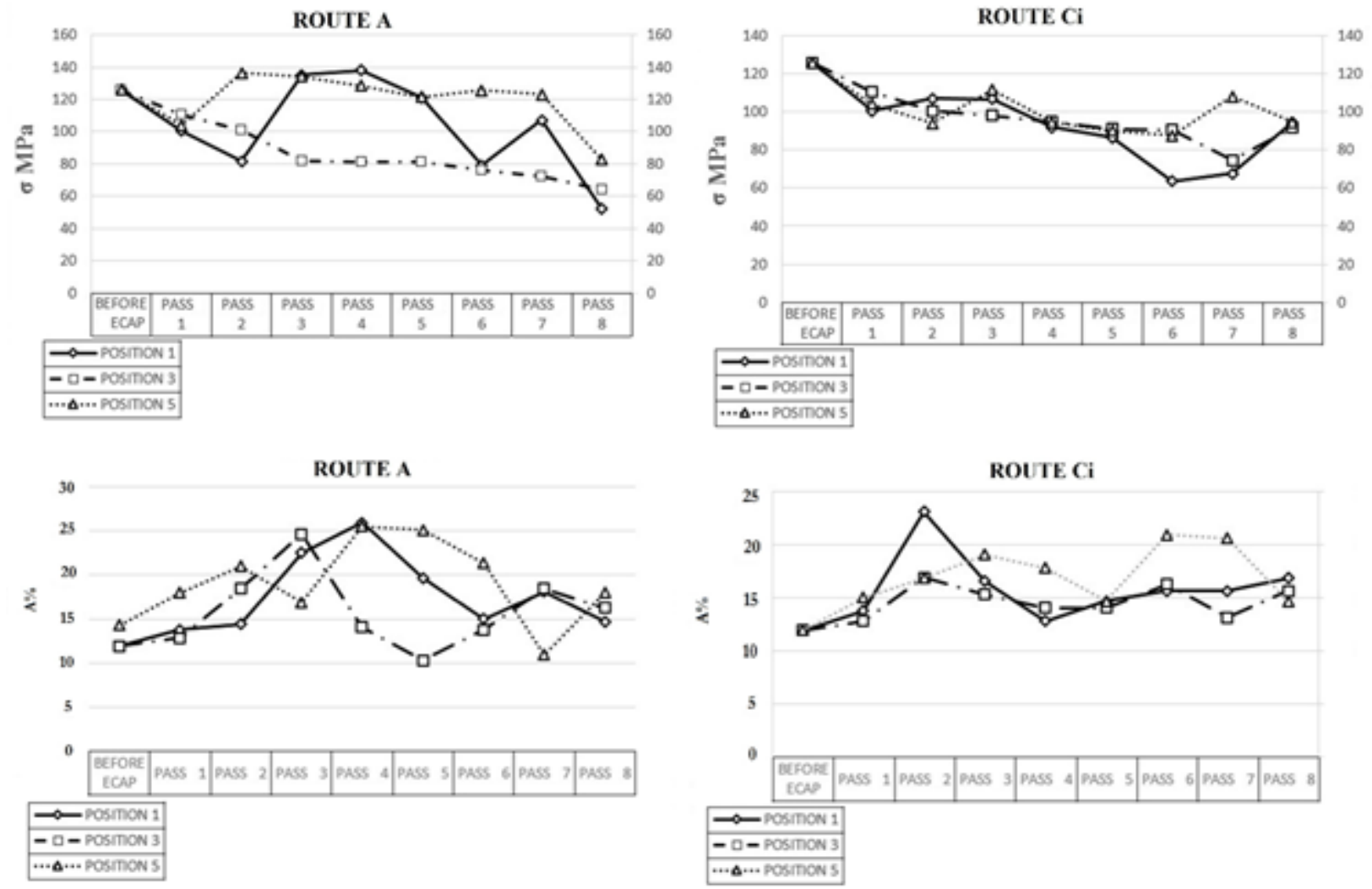

\section{Figure 10}

a.Ultimate tensile strength as a function of the number of passes.

b: Elongation to failure as a function of the number of passes. 

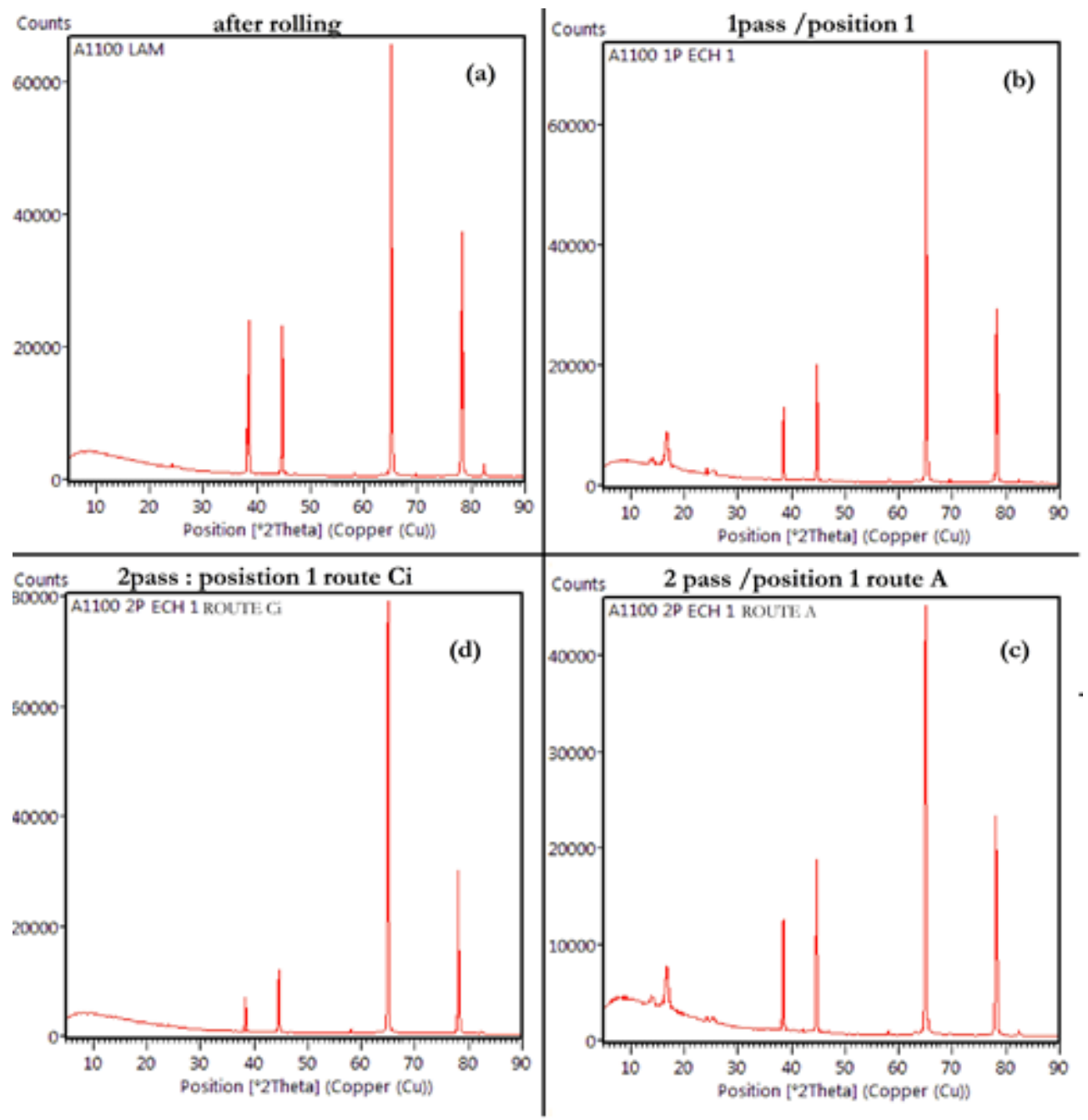

Figure 11

Diffraction peaks 